\title{
Interaction of Olive Oil Phenol Antioxidant Components with Low-density Lipoprotein
}

\author{
ROSA M. LAMUELA-RAVENTÓS ${ }^{1}$, EVA GIMENO ${ }^{1}$, MONTSE FITÓ ${ }^{2}$, ANA-ISABEL \\ CASTELLOTE $^{1}$, MARIBEL COVAS ${ }^{2}$, M. CARMEN DE LA TORRE-BORONAT ${ }^{1}$ and M. \\ CARMEN LÓPEZ-SABATER ${ }^{1}$.
}

\footnotetext{
${ }^{1}$ Department of Nutrition and Food Science, CèRTA, Faculty of Pharmacy, University of Barcelona, Spain ${ }^{2}$ Unitat de Lípids i Epidemiologia Cardiovascular, Institut Municipal d’Investigació Médica (IMIM), Barcelona, Spain
}

\begin{abstract}
Phenolic compounds have shown to inhibit LDL oxidation in vitro and ex vivo; however, they are hydrosoluble compounds while LDL is a lipoprotein. Analysis of phenolic compounds in LDLs by HPLC is necessary to demonstrate their binding capacity to lipoproteins. We developed and validated a solid phase extraction method (SPE) that allowed us the purification of LDL samples and their analysis by HPLC. This methodology allowed us to demonstrate the in vitro binding capacity of tyrosol, one of the main phenolic compounds in olive oil, to LDL. In the intervention dietary study with volunteers, food rich in phenolic compounds affected LDL composition. Changes in LDL phenolics composition are not observed after the short-term ingestion of food rich in phenolic compounds. However, after one week of olive oil consumption and Mediterranean diet there was an increase in phenolics $(\mathrm{p}=0.021)$. An accumulative effect seems necessary to observe significative differences in LDL phenolic composition.
\end{abstract}

Key words: Antioxidant, LDL, olive oil, oxidation, phenol, tyrosol.

\begin{abstract}
Abbreviations: CAE: caffeic acid equivalents; HPLC: high pressure liquid chromatography; LDL: lowdensity lipoprotein; MUFA: monounsaturated fatty acids; PUFA: polyunsaturated fatty acids; SFA: saturated fatty acids; SPE: solid phase extraction; VLDL: very low-density lipoprotein.
\end{abstract}

\section{INTRODUCTION}

Virgin olive oil is a fat that is very different from other fats, due to the way in which it is obtained and due to its composition. Regarding its obtainment, it is a fruit byproduct, while the more consumed oils (corn, wheat, etc.) come from seeds. The fruit processing necessary to obtain virgin olive oil includes only a physical treatment instead of a chemical one (extraction with organic solvents) and moreover, olive oil does not suffer the refination process, because it is a fat that can be consumed without any other treatment. Considering its composition, its major component is oleic acid. However, one of the main differences is that it contains natural phenols that come from the fruit and which are usually removed when the oil is refined (Caruso et al., 1999, Gimeno et al., 2002a).

Nowadays, cardiovascular diseases are still the main health concern in developed countries. However, the incidence is very different among developed countries, being the Mediterranean area, the one with the lowest rate (Sans et al., 1997; TunstallPodoe et al., 1999; Covas et al., 2001). Mediterranean countries consume high amounts of fat (at least $35 \%$ of consumed energy comes from fat) mainly as monounsaturated fatty acids (MUFA) present in olive oil (Serra-Majem, 1995).

Corresponding Author: Rosa M. Lamuela-Raventós. Department of Nutrition and Food Science, CèRTA, Faculty of Pharmacy, University of Barcelona, Av. Joan XXIII s/n, 08028- Barcelona, Spain. Phone: 34.934034843. Fax. 34.934035931.E-mail: lamuela@farmacia.far.ub.es 
Interaction of serum lipoproteins with vascular cells through oxidative processes, appears to be central to the formation of atherosclerotic lesions. LDL peroxidation is an essential step in the development and /or progression of atherosclerosis (Esterbauer et al., 1992; O'Bryne et al., 1998). The susceptibility of this particle to oxidation depends on its composition. LDL major components are cholesterol esters, triacylglycerols, phospolipids, and proteins. Diet can modify the LDL profile, not only in fatty acid composition, but also in the minor compounds that are present in LDL. Consumption of virgin olive oil, a fat that is characterized for its rich composition in MUFA and antioxidants (vitamin E, $\beta$ carotene and phenolic compounds) could decrease the susceptibility of LDL to oxidation (Mata et al., 1996; Nicolaiew et al., 1998; Ramírez-Tortosa et al., 1999; Gimeno et al., 2002b), possibly due to its enrichment in oleic acid and in minor compounds, present in the diet, that may bind to LDL.

Until now the effect of virgin olive oil phenolic compounds in LDL have been studied in vitro and in vivo evaluating the improvement of LDL resistance to oxidation (Caruso et al., 1999, Visioli and Galli, 1994, Visioli et al., 1995). When a phenolic olive oil extract has been incubated in vitro, a correlation between the inhibition of LDL oxidation and an increase in the concentration of tyrosol is observed (Covas et al., 2001; Fitó et al., 2000), that together with hydroxytryrosol is one of the main phenolic compounds present in virgin olive oil. These compounds are in the oil by themselves or in combination with elenoic acid, forming more complex structures. However, not many studies have focused on the changes in LDL phenolic profile. In 1995, Fuhrman et al. observed that after red wine consumption there is an increase in total phenols measured by Folin-Ciocalteu. This methodology is based on the capacity of phosphomolybdate and tungstate to form blue subspecies when being reduced by polyphenols, whose absorbance can be measured in the visible spectra. However, other readily oxidized substances can interfere in this reaction: sulfites, dehydroascorbic acid, tyrosine, tryptophane, etc (Singleton et al., 1999).

In 1999, Lamuela-Raventós et al. developed a method to determine phenolics in LDL. Two different extraction procedures were assayed, one using ethyl acetate as extractor solvent, and the other one using a new technique with solid phase extraction. Better results were obtained when solid phase extraction was used to separate plasma protein from phenols. Two quercetin-derived compounds could be identified in LDL. Quercetin is one of the polyphenols with higher antioxidant activity.

Here, changes in the amount of polyphenols and quercetin derivative in LDL after acute and short-term ingestion of virgin olive oil were evaluated.

\section{METHODS}

\section{Subjects}

Sixteen (nine men and seven women) healthy volunteers (aged 25 to 65) were recruited. The ethical committee CEICIMAS (register $n$ 98/798/I) approved the protocol and participants signed an informed consent form. On the basis of physical examination and standard biochemical and hematological tests, all volunteers were considered healthy. Subjects had an average weight of $75 \pm$ $13.47 \mathrm{~kg}$ and a body mass index of $25 \pm 3.1$ $\mathrm{kg} / \mathrm{m}^{2}$.

\section{Olive oil composition}

The only oil used in the study was of extravirgin quality and belonged to the appellation of Catalonia Les Garrigues. Acidity value, peroxide index and UV spectrophotometric index (k270) were determined following the analytical methods described in Regulations EEC/ 2568/91 of the European Union Commission. Fatty acids were transformed into trimethylesters and analyzed by gas chromatography (EEC/2568/91). $\alpha$ Tocopherol and $\beta$-carotene were determined by HPLC as previously described (Gimeno 
et al., 2000). Phenolic compounds were measured by the Folin-Ciocalteu method (Swain and Hillis, 1969).

\section{Study design}

Volunteers followed a phenolic-free diet for four days (washout period), before the administration of an acute dose of virgin olive oil. A nutritionist instructed them on excluding several foods from their diet (coffee, tea, fruits, vegetables, wine and olive oil). At 8 a.m. on day 5, subjects were given $50 \mathrm{ml}(44 \mathrm{~g})$ of extra-virgin olive oil in a single dose either alone or with bread. Subjects did not ingest any food or drink other than water in the first six hours after the meal and olive oil was the sole source of phenols over the following $24 \mathrm{~h}$. Blood samples were drawn on day 1 before the washout period (base line 1), on day 5 after washout (base line 2) and at 2, 4, 6, 8 and 24 hours after administering virgin oil. Thereafter, the participants followed their habitual diet supplemented by $25 \mathrm{ml} /$ day (22g) (individual dose provided to each subject) of the same olive oil for a week. Dietary fats from other sources were minimized. Subjects were instructed to exclude butter, margarine, cooking oil, nuts, visible fat of meat, chocolate, baked goods, eggs and poultry skin from their diets. Another blood sample was taken on day 12 at 8 a.m. All blood samples were stored at $-80^{\circ} \mathrm{C}$ until lipoprotein separation.

\section{Dietary survey}

Nutrient intakes were calculated from 12day dietary records using the software Diet Analysis Nutritionist IV (N Squared Computing, San Bruno, SA).

\section{Laboratory measurements}

Blood from healthy volunteers was collected in tubes containing $1 \mathrm{~g} / \mathrm{L}$ of EDTA and plasma was separated by centrifugation at $1000 \mathrm{~g}$ at $4^{\circ} \mathrm{C}$ for 15 minutes. Very low-density lipoproteins (VLDL) and LDL were isolated by sequential flotation ultracentrifugation (Havel et al., 1995). All samples were stored under $-80^{\circ} \mathrm{C}$ until analysis.
Phenolic compounds in LDL were determined by HPLC-DAD as described previously (Lamuela-Raventós et al., 1999). Briefly, acidulated LDL was applied to a Waters Oasis ${ }^{\mathrm{TM}}$ HLB extraction cartridge and washed with water and $5 \%$ aqueous methanol. Phenols were eluted with methanol, which was evaporated under a stream of nitrogen. The residue was dissolved in the mobile phase and injected into the HPLC system. The chromatogram was monitored at $280 \mathrm{~nm}$ and $365 \mathrm{~nm}$ and the phenolic areas were expressed as caffeic acid equivalents (CAE) for total phenols and as quercetin in the quercetin derivative peak.

\section{Statistical analysis}

The assays were carried out in duplicate. The values in the tables are given as means $\pm \mathrm{sd}$. The discussion is based on the oneway analysis of variance (ANOVA). Homogenicity of variances was tested by Levene's test. Logarithmic transformation was performed to normalize non-parametric variables. The differences between two groups were assessed by the Student's t test for paired samples. A $p$ value $<0.05$ was considered statistically significant. The SPSS statistical package was used (SPSS Incorporated Co., USA).

\section{RESULTS}

The daily caloric intake during the week of sustained olive oil ingestion ranged from 1465 to $2284 \mathrm{Kcal}$ (mean $1748 \pm 331$ ) and consisted of $44.2 \%$ carbohydrates $( \pm 5.1 \%)$, $18.3 \%$ proteins $( \pm 2.7 \%)$ and $37.5 \%$ lipids ( $\pm 3 \%$ ), of which $47.8 \%$ were MUFA, 39.2 $\%$ were SFA (saturated fatty acids) and 12.9 $\%$ were PUFA (Gimeno et al., 2002).

Olive oil quality parameters were within the limits accepted by its appellation (EEC/ 2081/92). The main fatty acid was oleic acid, which represents $73.27 \%$ of the fatty acids. Vitamin E level was $156 \mathrm{mg} / \mathrm{Kg}$ and total phenolics were $253 \mathrm{mg} / \mathrm{Kg}$ (CAE).

In Figure 1 are shown the results obtained in total phenols in LDLs. As it can be observed there is a decrease in the 


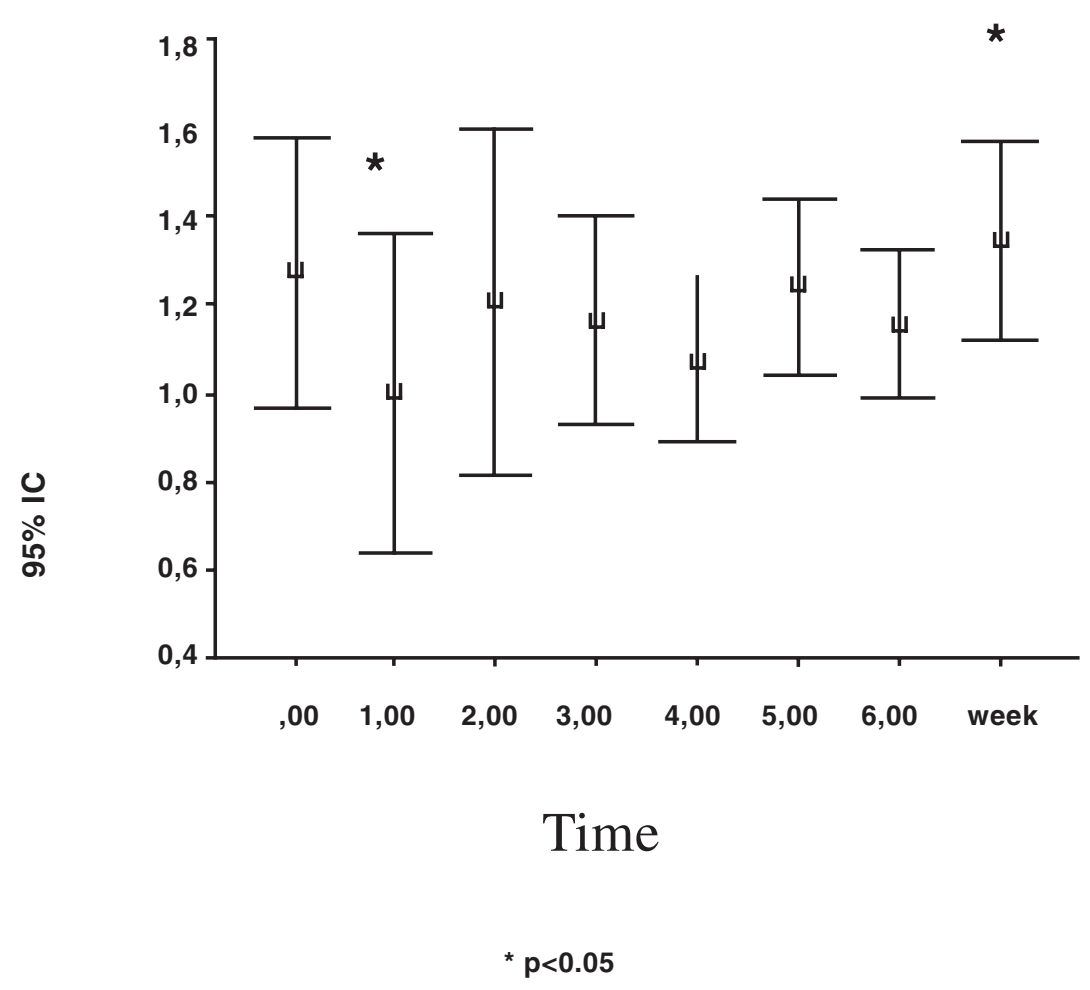

Figure 1. Changes in the total phenolic composition of LDL after an acute and short term ingestion of virgin olive oil. * Significative differences $(\mathrm{p}<0.05)$.

amount of total phenolics after the wash out period, since the participants had a phenolic free diet for 4 days. After the short term ingestion there is no modification in LDL phenolic composition. However, after one week of having olive oil and a Mediterranean diet, there is a significant increase $(\mathrm{p}<0.05)$ in the amount of total phenols. When one individual phenol (quercetin) is considered (Fig 2), there is an increase in the trend after one week; however, this increase is not statistically significative. The compounds follow the same pattern observed for total phenols: the changes are not statistically significative.

\section{CONCLUSIONS}

Diets rich in phenolic compounds, such as Mediterranean diet, including virgin olive oil, produce a significant modification in
LDL phenolic composition. These changes are not observed after the postprandial phase, however significative modification in the amount of phenolics is noticed after short-term ingestion (one week) of virgin olive oil accompanied with a Mediterranean diet. It seems that a daily ingestion of food rich in phenolic compounds is necessary to have an accumulative effect and to observe significant differences in the LDL phenolic composition.

\section{ACKNOWLEDGEMENTS}

This study was supported by the "Comisión Interministerial de Ciencia y Tecnología (ALI 97-1607-CO2-O2) and FEDER funds (2FD97-0297-CO2-O2). We thank all the volunteers for their cooperation and the staff members of the Hospital del Mar de Barcelona for their assistance. 


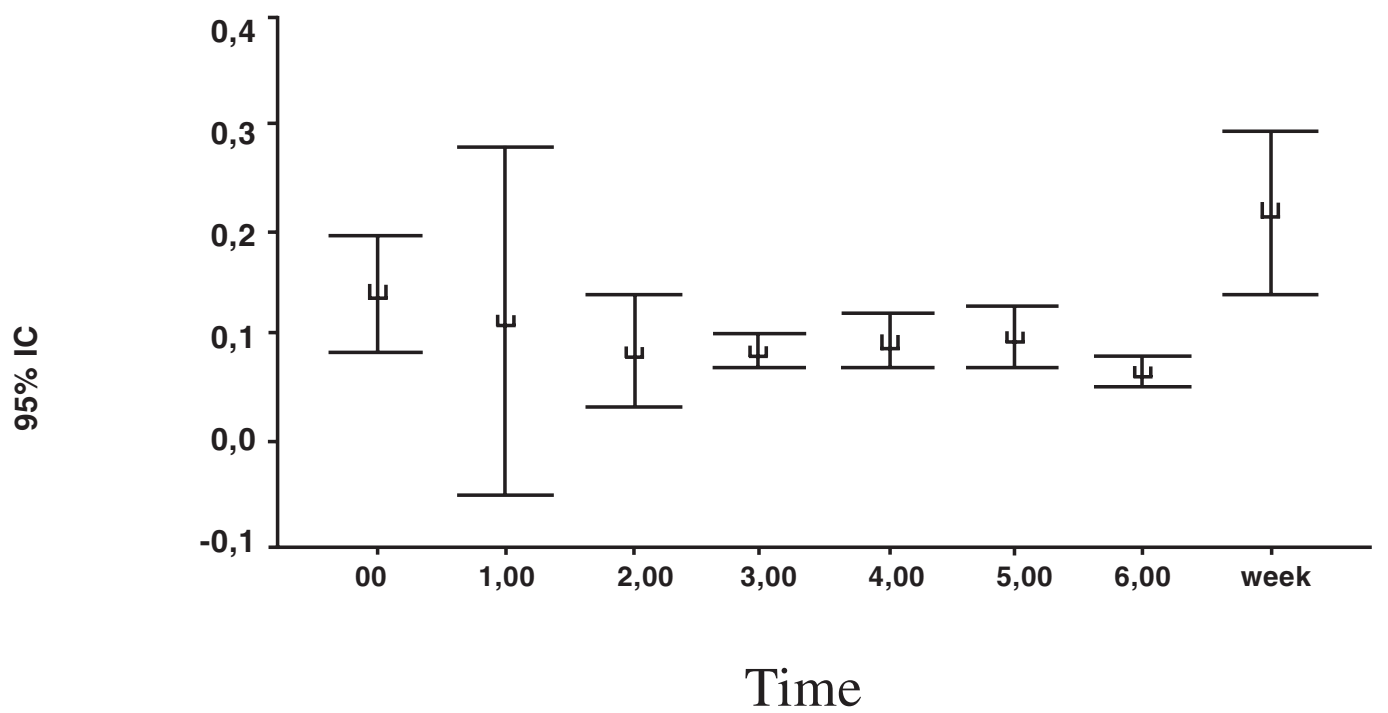

Figure 2. Changes in the quercetin derivative composition of LDL after an acute and short term ingestion of virgin olive oil.

\section{REFERENCES}

O’BYRNE DJ, O’KEEFE SF, SHIREMAN RB (1998) Low-fat, monounsaturated-rich diets reduce susceptibility of low-density lipoproteins to peroxidation ex vivo. Lipids 33: 149-156

CARUSO D, BERRA B, GIOVANINI F, CORTESI N, FEDELI E, GALLI G. (1999) Effect of virgin olive oil phenolic compounds on in vitro oxidation of human low density lipoproteins. Nutr Metab Cardiovasc Dis 9: 102-107

"COMMISSION REGULATION (EEC) n 2568/91 of July 111991 on the characteristics of olive oil and oliveresidue oil and on the relevant methods of analysis"

COVAS MI, FITÓ M, LAMUELA-RAVENTÓS RM, SEBASTIÀN, DE LA TORRE MC, MARRUGAT J (2000) Virgin olive oil phenolic compounds: binding to human LDL and effect on LDL oxidation. Int $\mathrm{J}$ Pharmacol Res 20: 49-54

ESTERBAUER H, PUHL H, DIEBER-ROTHENEDER M, WAEG G, RABL H (1991) Effect of antioxidants on oxidative modification of LDL. Ann Med 23: 573-581

ESTERBAUER H, GEBICKI J, PUHL H, JÜRGENS G (1992) The role of lipid peroxidation and antioxidants in oxidative modification of LDL. Free Rad Biol Med 13: $341-390$

FITÓ M, COVAS MI, LAMUELA-RAVENTÓS RM, VILA J, TORRENTS J, DE LA TORRE MC, MARRUGAT JC (2000) Protective effect of olive oil and its phenolic compounds against low density lipoprotein oxidation. Lipids 35: 633-638

FUHRMAN B, LAVY A, AVIRAM M (1995): Consumption of red wine with meals reduces the susceptibility of human plasma and low-density lipoprotein to lipid peroxidation. Am J Clin Nutr 61: 549-554.
GIMENO E, CALERO E, CASTELLOTE AI, LAMUELARAVENTÓS RM, DE LA TORRE MC, LÓPEZSABATER MC (2000) Simultaneous determination of $\alpha$-tocopherol and $\beta$-carotene in olive oil by RP-HPLC. J Chromatogr A 881: 255-259.

GIMENO E, CASTELLOTE AI, LAMUELA-RAVENTÓS RM, DE LA TORRE MC AND LÓPEZ-SABATER MC (2002a) The effect of harvest and extraction methods on the antioxidant content (phenolics, $\alpha$-tocopherol and $\beta$-carotene) in virgin olive oil. Food Chemistry 78: 207-211

GIMENO E, FITÓ M, LAMUELA-RAVENTÓS RM, CASTELLOTE AI, COVAS AI, FARRÉ M, DE LA TORRE MC AND LÓPEZ-SABATER MC (2002b) Effect of ingestion of virgin olive oil on human lowdensity lipoprotein composition. Eur J Clin Nutr 56: 114-120

HAVEL RJ, EDER HA, BRAGDAN JH (1995) The distribution and chemical composition of ultracentrifugally separated lipoproteins in human serum. J Clin Invest 4: 1345-1349.

LAMUELA-RAVENTÓS RM, COVAS MI, FITÓ M, MARRUGAT J AND DE LA TORRE-BORONAT (1999) Detection of dietary antioxidant phenolic compounds in human low density lipoproteins. Clin Chem 45: 1870-1872

MATA P, ALONSO R, LÓPEZ-FARRE A, ORDOVAS JM, LAHOZ C, GARCÉS C, CARAMELO C, COROCEO R, BLANQUEZ E, DE OYA M (1996) Effect of dietary fat saturation on LDL oxidation and monocyte adhesion to human endothelial cells in vitro. Arteriosc Thromb Vasc Biol 16: 1347-1355

NICOLAÏEW N, LEMORT $\mathrm{N}$, ADORNI L, BERRA B, MONTORFANO G, RAPELLI S, CORTESI N AND JACOTOT B (1998) Comparison between extra-virgin olive oil and oleic acid rich sunflower oil: Effects on 
postprandial lipemia and LDL susceptibility to oxidation. Ann Nutr Metab 42: 251-260

RAMÍREZ-TORTOSA MC, URBANO G, LÓPEZJURADO M, NESTARES T, GÓMEZ MC, MIR A, ROS E, MATAIX J, GIL A (1999): Extra-virgin olive oil increases the resistance of LDL to oxidation more than refined olive oil in free living men with peripheral vascular disease. J Nutr 129: 2177-2183

REGULATION ABOUT THE APPELLATION "Les Garrigues"(EEC/2081/92)

SANS S, KESTELLOT H, KROMHOUT D (on behalf of the task Force) (1997) Task force of the European Society of Cardiology and Cardiovascular Mortality and Morbidity Statistics in Europe. Eur Heart J 18: 1231-1248

SERRA-MAJEM L, RIBAS L, TRESERRAS R, NGO, SALLERAS L (1995): How could changes in diet explain changes in coronary heart disease mortality in Spain? The Spanish paradox. Am J Clin Nutr 61(s): $1351-1359$

SINGLETON VL, ORTHOFER R, LAMUELARAVENTÓS (1999) Analysis of total phenols and other oxidation substrates and antioxidants by means of Folin-Ciocalteu reagent. In PACKER L (ed) Methods in enzymology, Oxidants and antioxidants. Academic Press pp: $152-178$

SWAIN T, HILliS WE (1959) The phenolic constituents of Prunus domestica - 1 - The quantitative analysis of phenolic constituents J. Sci. Food Agric 10: 63-68

TUNSTALL-PEDOE H, KUULASMAA K, MAHONEN M, TOLONEN H, RUOKOKOSKI E, AMOUYEL P (1999) Contribution of trends in survival and coronaryevent rates to changes in coronary heart diseases mortality: 10-year results from 37 WHO MONICA Project populations. Lancet 353: 1547-1557

VISIOLI F, GALLI C (1994): Oleuropein protects lowdensity lipoprotein from oxidation. Life Sciences 55: 1965-1971

VISIOLI F, BELLOME G, MONTEDORO G AND GALLI C (1995): Low-density lipoprotein oxidation is inhibited in vitro by olive oil constituents. Atherosclerosis 117: 25-32 